\title{
Poly (ethylene terephthalate) synthesis with catalysts derived from chrysotile asbestos
}

\author{
Shigeki Habaue ${ }^{1 *}$, Yusuke Takahashi ${ }^{2}$, Yu Hosogoe $^{2}$, Hiroshi Yamashita ${ }^{2}$, Meisetsu Kajiwara ${ }^{3}$ \\ ${ }^{1}$ Faculty of Health and Nutrition, Shubun University, Ichinomiya, Japan; *Corresponding Author: habaue@shubun-ac.jp \\ ${ }^{2}$ Department of Chemistry and Chemical Enginerring, Graduate School of Science and Engineering, Yamagata University, Yonezawa, \\ Japan \\ ${ }^{3}$ School of Dentistry, Aichi-Gakuin University, Nagoya, Japan
}

Received 1 March 2010; revised 30 April 2010; accepted 13 May 2010.

\begin{abstract}
The chrysotile asbestos was converted to the forsterite-type compounds by calcination at $\mathbf{7 4 0}$ and $800^{\circ} \mathrm{C}$ (F7-740 and F7-800), which were used as a catalyst for the polycondensation of bis(hydroxyethyl) terephthalate affording poly (ethylene terephthalate). The obtained forsterite-type compounds did not show any catalytic activity. However, the products obtained by simply treating them with acetic acid significantly pro- moted the polymerization that produced a THF- insoluble polymer. It was found that the polymer prepared with the acetic acid-treated F7-740 at $160^{\circ} \mathrm{C}$ for $2 \mathrm{~h}$ showed a $93 \%$ yield and the number average molecular weight of $6.4 \times 10^{3}$. The observed catalytic activity was higher than that for the acetic acid-treated magnesium oxide, as well as the typical polycondensation catalysts, such as magnesium acetate and antimony oxide.
\end{abstract}

Keywords: Chrysotile Asbestos Forsterite; Polycondensation; Poly (Ethylene Terephthalate); Recycling

\section{INTRODUCTION}

Poly(ethylene terephthalate) (PET) is a versatile thermoplastic resin and extensively used for various products in the forms of fibers, films, etc. The PET is generally produced by the esterification of terephthalic acid with ethylene glycol followed by polycondensation, as well as by transesterification using dimethyl terephthalate with ethylene glycol or using bis(hydroxyethyl) terephthalate (BHET) as the starting material. The latter system with BHET is also important as one of the recycling processes of PET wastes, which is shown in Scheme 1.

During these polycondensation processes, antimony compounds, such as the oxide and acetate, are typically employed as the catalyst [1-4], and the replacing these heavy metal catalysts with others that are safe, economic, and highly catalytic has been desired [5-7]. For example, it was recently reported that hydrotalcite, $\left[\mathrm{Mg}_{6} \mathrm{~A}_{12}(\mathrm{OH})_{16}\right]$ $\left(\mathrm{CO}_{3}\right) \cdot 4 \mathrm{H}_{2} \mathrm{O}$, can be an efficient catalyst for the PET synthesis [8,9].

The chrysotile asbestos, represented by the approximate composition of $\mathrm{Mg}_{3} \mathrm{Si}_{2} \mathrm{O}_{4}(\mathrm{OH})_{4}$, is comprised of a silica tetrahedral sheet $\left[\mathrm{SiO}_{4}\right]$ joined into a brucite layer of basic magnesium hydroxide $\left[\mathrm{Mg}(\mathrm{OH})_{2}\right]$, and the curvature of these layers affords a structure of tubular and cylindrical rolls with nanometer-order diameters [10]. The chrysotile asbestos has been widely applied in industry as a material having excellent physical and chemical properties, such as tensile strength, heat-resistance, durability, etc. However, its use is prohibited or strictly regulated at present, because of health hazards, that is, asbestosis and carcinogenesis of respiratory systems.

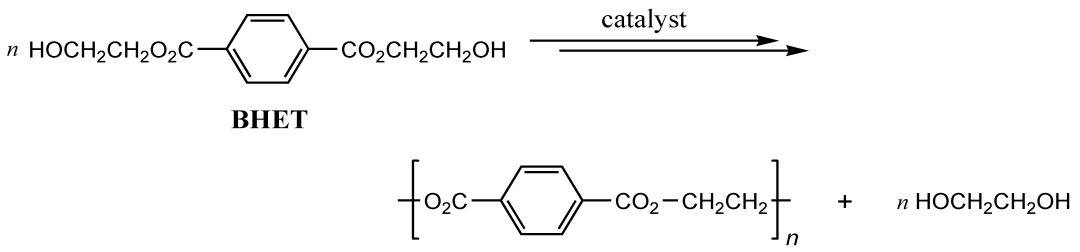

PET

Scheme 1. Polycondensation of BHET producing PET. 
The fibrous and needle-like structure of the asbestos is considered to be the main cause of these serious diseases. A vast amount of chrysotile asbestos has already been used, therefore, the development of potential disposal methods for these waste materials and the unused raw chrysotile is an essential and urgent subject. Especially, their transformation into nontoxic and valuable materials is of great significance.

Recently, we reported that chrysotile asbestos is effectively converted into polysiloxanes through selective acid-leaching and silylation $[11,12]$. This result offers a novel method for converting the hazardous chrysotile asbestos wastes into valuable polymer materials. The calcination of the chrysotile asbestos is another method affording a harmless material, which mainly consists of forsterite, $\mathrm{Mg}_{2} \mathrm{SiO}_{4}$, as shown in Scheme 2 [13-15]. Accordingly, effective utilization of this material can also provide a certain way to solve this serious issue.

$$
\begin{aligned}
& 2 \mathrm{Mg}_{3} \mathrm{Si}_{2} \mathrm{O}_{5}(\mathrm{OH})_{4} \longrightarrow \longrightarrow \\
& 3 \mathrm{Mg}_{2} \mathrm{SiO}_{4}+\mathrm{SiO}_{2}+4 \mathrm{H}_{2} \mathrm{O}
\end{aligned}
$$

Scheme 2. Calcination process of chrysotile asbestos.

In this study, the forsterite-type compounds prepared by the calcination of the chrysotile asbestos were evaluated as the polycondensation catalyst for BHET, and it was found that they show a significant catalytic activity by treating with carboxylic acids. Therefore, this novel catalyst system for the PET production from BHET can simultaneously contribute to the effective recycling both of the asbestos and PET wastes.

\section{EXPERIMENTAL}

\subsection{Materials}

The class 7 chrysotile (F7) [mined in Furano, Hokkaido, Japan (Nozawa Co.)] was used as the starting material, and the calcination at 800 or $740^{\circ} \mathrm{C}$ for $1 \mathrm{~h}$ was conducted to produce a pale brownish, forsterite-type compound, F7-800 or F7-740 (caution!: the asbestos must be carefully treated, because the fibrils cause serious health hazards). The silica ( $\left.\mathrm{L}-\mathrm{SiO}_{2}\right)$ with a fibrous structure originating from the chrysotile was prepared by the acid-leaching of the serpentine slag with sulfuric acid as previously reported $[11,12]$. During this process, almost all of the magnesium constituent was removed, that is, the brucite layer was effectively leached. Its chemical composition ( $\%$, fluorescent X-ray) was estimated to be 96.6, $\mathrm{SiO}_{2} ; 2.4, \mathrm{Al}_{2} \mathrm{O}_{3} ; 0.2, \mathrm{Fe}_{2} \mathrm{O}_{3} ; 0.1, \mathrm{CaO}$, and it has a specific surface area of $178 \mathrm{~m}^{2} / \mathrm{g}$. The monomer, BHET (TCI), and the salts of magnesium and antimony, such as
$\mathrm{MgO}, \mathrm{Mg}(\mathrm{OH})_{2}$, magnesium acetate $\left[\mathrm{Mg}(\mathrm{OAc})_{2}\right]$ (Kanto), $\mathrm{MgSO}_{4}$ (Wako), and $\mathrm{Sb}_{2} \mathrm{O}_{3}$ (Nihon Seiko), were used as received.

\subsection{Treatment of Forsterite with Acid}

A mixture of the forsterite-type compound $(0.20 \mathrm{~g}$, F7-800 or F7-740) and acetic acid (7 equiv. based on Mg) was stirred for $24 \mathrm{~h}$ under a $\mathrm{N}_{2}$ atmosphere at ambient temperature. After evaporation of the acid, the product was further vacuum-dried at $50^{\circ} \mathrm{C}$ for $12 \mathrm{~h}$. The obtained solid was used for the polycondensation reaction as the catalyst without further purification.

\subsection{Polymerization}

A mixture of BHET $(0.50 \mathrm{~g})$ and a catalyst $(1 \mathrm{wt} \%)$ was reacted at $160^{\circ} \mathrm{C}$ for $2 \mathrm{~h}$ under reduced pressure $(<0.5$ $\mathrm{mmHg}$ ). After cooling to room temperature, the reaction mixture was washed with methanol, then with tetrahydrofuran (THF). The insoluble fraction was isolated by centrifugation and dried in vacuo.

\subsection{Measurements}

The chemical compositions were determined by X-ray fluorescence using a Shimadzu EDX-800 spectrometer. The specific surface area was measured by the BET method. The powder X-ray diffraction (XRD) patterns were obtained using monochromatic $\mathrm{CuKa}$ radiation with a Rigaku RINT-2100-ultra diffractometer. The ${ }^{1} \mathrm{H}$ NMR spectra were measured by a Varian Unity Inova (500 MHz) spectrometer. The infrared (IR) spectra were recorded by a Horiba FT-720 spectrometer. The size exclusion chromatography (SEC) analysis was performed by a Jasco PU-2080-plus equipped with a Jasco UV2075-plus UV detector with Shodex AC8025 and TSKGEL columns connected in series (eluent $=\mathrm{CHCl}_{3}$, flow rate $=1.0 \mathrm{~mL} / \mathrm{min}$ ). The polymers were dissolved in $\mathrm{CHCl}_{3}$ by addition of a small amount of 1,1,1,3,3,3hexafluoroisopropanol (HFIP) and calibration was carried out with standard polystyrenes.

\section{RESULTS AND DISCUSSION}

\subsection{Calcination of Chrysotile Asbestos}

The XRD patterns of F7-800 and F7-740, prepared by the calcination of the chrysotile asbestos at 800 and $740^{\circ} \mathrm{C}$ for $2 \mathrm{~h}$ under atmospheric pressure, are shown in Figure 1. The peaks based on the chrysotile completely disappeared during the calcination, and peaks due to the formation of forsterite were observed for both products. The compound calcined at the lower temperature, F7740 , showed a broader peak pattern than that of F7-800, suggesting that the calcination temperature affects the 


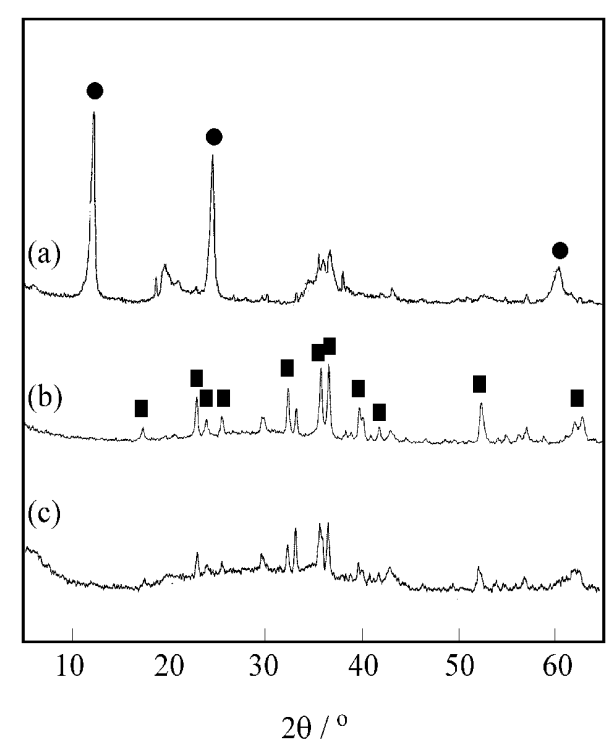

Figure 1. X-ray powder diffraction patterns of (a) chrysotile asbestos (serpentine slag), (b) F7-800, and (c) F7-740 ( $\bullet$ : chrysotile, forsterite).

crystallinity of the products. The product, F7-740, should have a lower crystallinity than F7-800.

The chemical composition, determined by a fluorescent X-ray analysis, and specific surface area of the sta- rting material $\mathrm{F} 7$ and the calcined products, $\mathrm{F} 7-800$ and F7-740, are listed in Table 1. The amounts $\mathrm{MgO}, \mathrm{SiO}_{2}$, $\mathrm{Fe}_{2} \mathrm{O}_{3}, \mathrm{Al}_{2} \mathrm{O}_{3}$, and $\mathrm{CaO}$ in the products $(\mathrm{F} 7-800$ and F7-740) increased by the calcinations when compared to those of F7. This is due to the dehydration as shown in Scheme 2. The observed chemical compositions for the calcined products are quite similar to each other, while the BET surface area of $F 7-740,25.1 \mathrm{~m}^{2} / \mathrm{g}$, was higher than that of F7-800. These results showed that the calcination temperature should affect the crystallinity. In other words, the product, F7-740, is rich in an amorphous phase.

\subsection{Polycondensation of Bis(hydroxyethyl) Terephthalate}

The polymerization of BHET at $160^{\circ} \mathrm{C}$ under vacuum was carried out (Table 2). The polymerization without a catalyst did not proceed (entry 1). The typical magnesium and antimony salts, such as $\mathrm{MgO}, \mathrm{Mg}(\mathrm{OH})_{2}$, $\mathrm{Mg}(\mathrm{OAc})_{2}$ and $\mathrm{Sb}_{2} \mathrm{O}_{3}$, except for $\mathrm{MgSO}_{4}$, as the catalyst promoted the polymerization and produced the THF-insoluble polymers (entries 4-8). For example, $\mathrm{Mg}(\mathrm{OAc})_{2}$ afforded a polymer in a good yield with the number average molecular weight $\left(M_{\mathrm{n}}\right)$ of $6.2 \times 10^{3}$. However, the forsterite-type compounds, F7-800 and F7-740, which mainly contain the magnesium constituent, did not afford any polymeric compounds (entries 2 and 3 ).

Table 1. Characterization of starting materials.

\begin{tabular}{ccccccc}
\hline & \multicolumn{9}{c}{ Chemical composition $(\%)^{\mathrm{a}}$} & \multirow{2}{*}{$\begin{array}{c}\text { Surface area } \\
\left(\mathrm{m}^{2} / \mathrm{g}\right)^{\mathrm{b}}\end{array}$} \\
\cline { 2 - 6 } Material & $\mathrm{MgO}$ & $\mathrm{SiO}_{2}$ & $\mathrm{Fe}_{2} \mathrm{O}_{3}$ & $\mathrm{Al}_{2} \mathrm{O}_{3}$ & $\mathrm{CaO}$ & - \\
$\mathrm{nyyyyn}$ & 50.5 & 29.7 & 3.7 & 1.0 & 0.4 & 18.2 \\
$\mathrm{~F} 7-800$ & 58.9 & 32.9 & 4.1 & 1.3 & 0.5 & 25.1 \\
F7-740 & 57.9 & 32.6 & 4.0 & 1.3 & 0.5 & \\
\hline
\end{tabular}

${ }^{\mathrm{a}}$ Determined by fluorescent X-ray analysis. ${ }^{\mathrm{b}}$ Determined by BET measurement.

Table 2. Polymerization of BHET with various catalysts at $160^{\circ} \mathrm{C}$.

\begin{tabular}{|c|c|c|c|c|c|}
\hline Entry & Catalyst $^{\mathrm{a}}$ & Yield $(\%)^{b}$ & $\begin{array}{c}\text { Activity } \\
(\text { g-product } \cdot \text { g-cat } \\
\left.\text { - }^{-1} \cdot \mathrm{h}^{-1}\right)\end{array}$ & $M_{\mathrm{n}} \times 10^{-3 \mathrm{c}}$ & $M_{\mathrm{w}} \times 10^{-3 \mathrm{c}}$ \\
\hline 1 & - & 0 & - & - & - \\
\hline 2 & F7-800 & 0 & - & - & - \\
\hline 3 & F7-740 & 0 & - & - & - \\
\hline 4 & $\mathrm{MgO}^{\mathrm{d}}$ & 21 & 26.3 & 3.4 & 4.0 \\
\hline 5 & $\mathrm{Mg}(\mathrm{OH})_{2}{ }^{\mathrm{e}}$ & 55 & 45.8 & 4.9 & 5.7 \\
\hline 6 & $\mathrm{Mg}(\mathrm{OAc})_{2}$ & 87 & 43.5 & 6.2 & 7.2 \\
\hline 7 & $\mathrm{MgSO}_{4}{ }^{\mathrm{f}}$ & 0 & - & - & - \\
\hline 8 & $\mathrm{Sb}_{2} \mathrm{O}_{3}$ & 22 & 11.0 & 4.9 & 5.4 \\
\hline 9 & $\mathrm{~L}-\mathrm{SiO}_{2}$ & 0 & - & - & - \\
\hline
\end{tabular}

${ }^{\mathrm{a} B H E T}$ : $0.50 \mathrm{~g}$, catalyst: $5 \mathrm{mg}$. ${ }^{\mathrm{b}} \mathrm{MeOH}-$ and THF-insoluble part. ${ }^{\mathrm{c}}$ Determined by SEC (polystyrene standards). ${ }^{\mathrm{d}} \mathrm{MgO}: 2 \mathrm{mg}$. ${ }^{\mathrm{e}} \mathrm{Mg}(\mathrm{OH})_{2}: 3 \mathrm{mg} .{ }^{\mathrm{f}} \mathrm{MgSO}_{4}: 6 \mathrm{mg}$. 
F7-800 and F7-740 were then treated with acetic acid $(\mathrm{AcOH})$ at room temperature as stated in the experimental section, and the obtained compounds were used as the polycondensation catalyst. During this process, the weight increases of $1.8 \times 10^{2}$ and $3.3 \times 10^{2} \mathrm{mg}$ for $1.0 \mathrm{~g}$ of F7-800 and F7-740, respectively, were observed. The IR spectra of these compounds are shown in Figure 2, together with those of F7-740 and $\mathrm{Mg}(\mathrm{OAc})_{2}$. The absorptions based on the magnesium acetate around $1100-1300 \mathrm{~cm}{ }^{1}$ were clearly observed for F7-800 and F7-740 when treated with AcOH. Accordingly, during this process, the formation of the magnesium salt of $\mathrm{AcOH}$ should take place, whereas the yields were poor, judging from the observed weight increase.

On the other hand, $\mathrm{MgO}$ was also treated with $\mathrm{AcOH}$ (12 equiv.) to give a reaction mixture, which showed a weight increase of $3.0 \times 10^{3} \mathrm{mg}$ for $1.0 \mathrm{~g}$ of $\mathrm{MgO}$. The leached silica, $\mathrm{L}_{-} \mathrm{SiO}_{2}$, prepared from the serpentine slag $[11,12]$, was calcined at $740^{\circ} \mathrm{C}$ for $1 \mathrm{~h}$, and it was also treated with 5 equiv. of $\mathrm{AcOH}$. However, no weight increase was observed. These results were quite different from those observed for F7-800 and F7-740, supporting the fact that the magnesium constituent in the forsterite-type compounds should react with $\mathrm{AcOH}$.

The results of the polycondensation of BHET with the catalyst $(1 \mathrm{wt} \%)$, prepared from the forsterite-type compounds by treating with various organic carboxylic acids, are summarized in Table 3. The $\mathrm{MgO}$ derivative, obtained by treating with $\mathrm{AcOH}$, produced a polymer in $84 \%$ yield and showed an catalytic activity of 42.0 g-product/g-cata- lyst $\cdot h$ (Table 3, entry 1), whose values were almost comparable to those of the polymerization using $\mathrm{Mg}(\mathrm{OAc})_{2}$ (Table 2, entry 6). The acid-treated $\mathrm{L}_{-} \mathrm{SiO}_{2}$, as well as the original $\mathrm{L}-\mathrm{SiO}_{2}$, produced no THF-insoluble fraction during the polymerization (Table 3, entry 11 and Table 2, entry 9).

In marked contrast, the F7-800 and F7-740 derivatives, treated with $\mathrm{AcOH}$, resulted in good yields with the $M_{\mathrm{n}}$ value of approximately $6.3 \times 10^{3}$ (Table 3, entries 2 and 3), although F7-800 and F7-740 without acid-treatment showed no catalyst activity (Table 2 , entries 2 and 3 ). Especially, the AcOH-treated F7-740 showed the higher

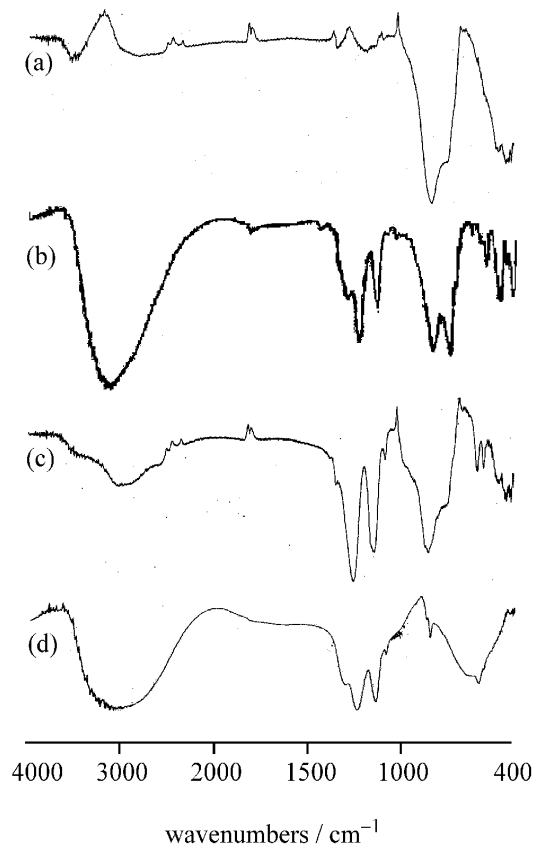

Figure 2. IR spectra of (a) F7-740, (b) F7-800 after treating with $\mathrm{AcOH}$, (c) F7-740 after treating with $\mathrm{AcOH}$ at room temperature, and (d) $\mathrm{Mg}(\mathrm{OAc})_{2}(\mathrm{KBr})$.

Table 3. Polymerization of BHET with various acid-treated materials at $160^{\circ} \mathrm{C}^{\mathrm{a}}$.

\begin{tabular}{ccccccc}
\hline Entry & $\begin{array}{c}\text { Starting } \\
\text { material }\end{array}$ & Acid & Yield (\%) & $\begin{array}{c}\text { Activity } \\
\left(\text { g-product } \cdot \text {-cat }^{-1} \cdot \mathrm{h}^{-1}\right)\end{array}$ & $M_{\mathrm{n}} \times 10^{-3 \mathrm{~d}}$ & $M_{\mathrm{w}} \times 10^{-3 \mathrm{~d}}$ \\
\hline 1 & $\mathrm{MgO}$ & $\mathrm{AcOH}$ & 84 & 42.0 & 5.3 & 5.9 \\
2 & $\mathrm{~F} 7-800$ & $\mathrm{AcOH}$ & 71 & 35.5 & 6.3 & 7.5 \\
3 & $\mathrm{~F} 7-740$ & $\mathrm{AcOH}$ & 93 & 46.5 & 6.4 & 7.6 \\
$4^{\mathrm{e}}$ & $\mathrm{F} 7-740$ & $\mathrm{AcOH}$ & 90 & 45.0 & 13.1 & 20 \\
$5^{\mathrm{f}}$ & $\mathrm{F} 7-740$ & $\mathrm{AcOH}$ & 68 & 56.7 & 5.1 & 5.6 \\
$6^{\mathrm{f}}$ & $\mathrm{F} 7-740$ & $\mathrm{AcOH}^{\mathrm{g}}$ & 77 & 64.2 & 5.0 & 5.5 \\
$7^{\mathrm{f}}$ & $\mathrm{F} 7-740$ & $\mathrm{AcOH}^{\mathrm{h}}$ & 80 & 66.7 & 5.2 & 5.8 \\
8 & $\mathrm{~F} 7-740$ & $\mathrm{PA}^{\mathrm{h}, \mathrm{i}}$ & 46 & 23.0 & 5.7 & 6.9 \\
9 & $\mathrm{~F} 7-740$ & $\mathrm{TFA}^{\mathrm{j}}$ & 62 & 31.0 & 5.2 & 5.9 \\
10 & $\mathrm{~F} 7-740_{11}^{\mathrm{g}}$ & $\mathrm{TFA}^{\mathrm{g} . \mathrm{j}}$ & 48 & 21.5 & -7 & 5.3 \\
\hline
\end{tabular}

${ }^{\mathrm{a} B H E T}$ : $0.50 \mathrm{~g}$, catalyst: $5 \mathrm{mg}$. ${ }^{\mathrm{b}}$ About 7 equiv. of acid was used. ${ }^{\mathrm{c}} \mathrm{MeOH}-$ and THF-insoluble part. ${ }^{\mathrm{d}}$ Determined by SEC (polystyrene standards). ${ }^{\mathrm{e}}$ Reaction temp. $=220^{\circ} \mathrm{C}$. ${ }^{\mathrm{f}} \mathrm{Catalyst}: 3 \mathrm{mg} .{ }^{\mathrm{g}} \mathrm{F} 7-740$ was treated with $\mathrm{AcOH}$ at $60^{\circ} \mathrm{C} .{ }^{\mathrm{h}} \mathrm{F} 7-740$ was treated with $\mathrm{AcOH}$ at $100^{\circ} \mathrm{C}$. ${ }^{i}$ Propionic acid. ${ }^{j}$ Trifluoroacetic acid. ${ }^{k} \mathrm{~L}-\mathrm{SiO}_{2}$ calcinated at $740^{\circ} \mathrm{C}$ was used. 
yield of $93 \%$ and a catalytic activity of $46.5 \mathrm{~g}$-product/ g-catalyst $\cdot h$ than those of the acid-treated $\mathrm{MgO}$ derivative, as well as those of $\mathrm{Mg}(\mathrm{OAc})_{2}$, although the weight increase of F7-740 during the AcOH-treatment step was much lower than that of $\mathrm{MgO}$. These results suggest that the activity of the catalyst sites in the F7-740, generated during the acid-treatment process, should be significantly high when compared to that of the acid-treated $\mathrm{MgO}$ and $\mathrm{Mg}(\mathrm{OAc})_{2}$. Therefore, in addition to the formation of the magnesium salt of $\mathrm{AcOH}$ in F7-740, some structure of the forsterite, prepared from the chlysotile asbestos, should play an important role in the polycondensation of BHET.

The polymerization of BHET with the AcOH-treated F7-740 was performed at $220^{\circ} \mathrm{C}$ (Table 3, entry 4). Although the observed polymer yield and catalytic activity were similar to those of the polymerization at $160^{\circ} \mathrm{C}$, the obtained polymer showed an $M_{\mathrm{n}}$ value of $1.3 \times 10^{4}$, which was estimated by SEC. Therefore, the polymerization at higher temperatures could be effective for this catalyst system.

The ${ }^{1} \mathrm{H}$ NMR spectrum of the THF-insoluble part obtained using the AcOH-treated F7-740 (Table 3, entry 4) was depicted in Figure 3. The polymer was soluble in chloroform containing a small amount of HFIP, and the peaks were assigned as shown in the figure. The small peaks around 4.0 and $4.5 \mathrm{ppm}$ were based on the methylene protons of the terminal hydroxyethoxy groups (Scheme 3). Accordingly, the $M_{\mathrm{n}}$ value calculated from the integral ratio was $2.5 \times 10^{3}$, which is much lower than that estimated by SEC, probably due to the rigid aromatic main chain of the polymer and some aggregation.

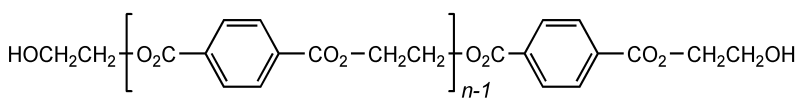

Scheme 3. Structure of the obtained PET.

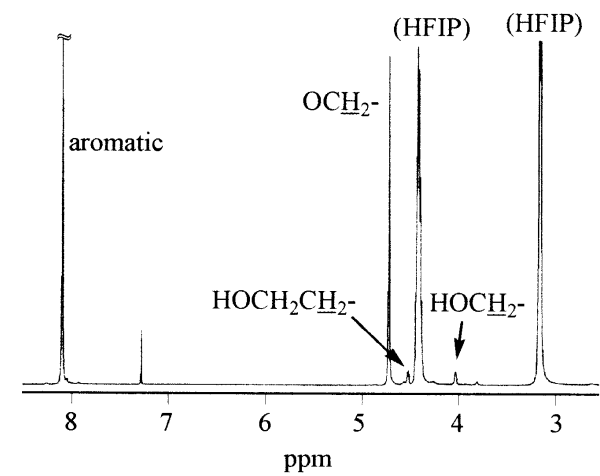

Figure 3. ${ }^{1} \mathrm{H}$ NMR Spectrum of the obtained polymer (Table 3, entry 4) (in $\mathrm{CDCl}_{3}$ containing HFIP).
The forsterite-type compound, F7-740, was treated with heated $\mathrm{AcOH}$ for $24 \mathrm{~h}$. During this process, the weight increases of $6.1 \times 10^{2}$ and $9.3 \times 10^{2} \mathrm{mg} / \mathrm{g}-\mathrm{F} 7-740$ for the reaction at 60 and $100^{\circ} \mathrm{C}$, respectively, were observed. Therefore, the reaction between the magnesium in the compound and $\mathrm{AcOH}$ proceeded more effectively than the reaction at room temperature. The obtained materials were employed as the catalyst $(0.6 \mathrm{wt} \%)$ for the polymerization of BHET at $160^{\circ} \mathrm{C}$ (Table 3, entries 5-7). Under these reaction conditions, the acid-treated F7-740 at room temperature showed a catalytic activity of 56.7 g-product/g-catalyst $\cdot h$, whereas the F7-740 derivatives, treated with $\mathrm{AcOH}$ at higher temperatures, showed significantly higher catalytic activities. For example, the highest activity of 66.7 g-product/g-catalyst.h was observed for the polymerization using the F7-740 derivative prepared at $100^{\circ} \mathrm{C}$.

F7-740 was further ground and treated with $\mathrm{AcOH}$ at $100^{\circ} \mathrm{C}$ for $24 \mathrm{~h}$. The weight increase was $1.1 \times 10^{3}$ $\mathrm{mg} / \mathrm{g}-\mathrm{F} 7-740$, which is higher than that observed for the reaction of F7-740 without grinding. The polycondensation of BHET at $160^{\circ} \mathrm{C}$ with this catalyst $(0.6 \mathrm{wt} \%)$ was conducted, and the THF-insoluble fraction was obtained in a $72 \%$ yield with the catalytic activity of $60.0 \mathrm{~g}$ product $/ g$-catalyst $\cdot h$ and the $M_{\mathrm{n}}$ of $5.4 \times 10^{3}$ as evaluated by SEC. This result was almost comparable to that of the polymerization using the acid-treated F7-740 without grinding.

Finally, the effect of the carboxylic acid on the catalytic activity during the BHET polymerization at $160^{\circ} \mathrm{C}$ (catalyst: $1 \mathrm{wt} \%$ ) was examined (Table 3, entries 8-10). The forsterite-type material, F7-740, was treated with propionic acid (PA) at $100^{\circ} \mathrm{C}$. After evaporation of the unreacted acid, the weight increase was $9.4 \times 10^{2} \mathrm{mg} / \mathrm{g}$ F7-740, of which the molar yield is lower than that observed for the reaction with $\mathrm{AcOH}$ at $100^{\circ} \mathrm{C}$. The acidity of the carboxylic acid should have an effect on the reaction. The polymerization with this catalyst resulted in a much lower yield and catalytic activity than those for the polymerization using the AcOH-treated F7-740 catalyst. F7-740 was also treated with trifluoracetic acid (TFA) at room temperature or $60^{\circ} \mathrm{C}$ affording a reaction mixture with the weight increase of $9.2 \times 10^{2}$ or $2.6 \times 10^{3} \mathrm{mg} / \mathrm{g}$ F7-740, respectively. The latter catalyst preparation reaction at $60^{\circ} \mathrm{C}$ significantly proceeded, however, it showed a low catalytic activity of 21.5 g-product/g-catalyst $\cdot h$ for the polymerization. Therefore, $\mathrm{AcOH}$ is currently the most effective carboxylic acid, that is, the magnesium salt of $\mathrm{AcOH}$ generated in the forsterite-type compound, F7-740, effectively promotes the polycondensation of BHET, although a detail structure of the active site is not clear at present. 


\section{CONCLUSIONS}

The chrysotile asbestos was calcined affording the forsterite-type compounds. Although the polycondensation of BHET with them did not proceed, the compounds, just treated with acetic acid, showed a significant catalytic activity, which was higher than that for the polymerization by the $\mathrm{MgO}$ derivative treated with acetic acid, as well as typical polycondensation catalysts, such as $\mathrm{Mg}(\mathrm{OAc})_{2}$ and $\mathrm{Sb}_{2} \mathrm{O}_{3}$. Some phases or amorphologies having the composition of the forsterite derived from the chrysotile asbestos by the calcination, in addition to the magnesium salt generated by acid-treatment, should be important for the catalytic activity during the polymerization. Accordingly, this novel catalyst system could contribute to both the disposal of chrysotile asbestos waste and the recycling of PET waste.

\section{REFERENCES}

[1] El-Toufaili, F.-A., Feix, G. and Reichert, K.-H. (2006) Mechanistic investigations of antimony-catalyzed polycondensation in the synthesis of poly(ethylene terephthalate). Journal of Polymer Science Part A: Polymer Chememistry, 44(3), 1049-1059.

[2] Lee, S.W., Ree, M., Park, C.E., Jung, Y.K., Park, C.-S., Jin, Y.S. and Bae, D.C. (1999) Synthesis and non-isothermal crystallization behaviors of poly(ethylene isophthalate-co-terephthalate)s. Polymer, 40(25), 7137-7146.

[3] Zhang, Y. and Gu, L. (2000) Study of non-isothermal crystallization kinetics and sequence distribution in poly (ethyele terephthalate-co-isophthalate). European Polymer Jounal, 36(5), 759-765.

[4] Greener, J., Gillmor, J.R. and Daly, R.C. (1993) Melt rheology of a class of polyester ionomers. Macromolecules, 26(24), 6416-6424.

[5] MacDonald, W.A. (2002) New advances in poly(ethylene terephthalate) polymerization and degradation. Polymer
International, 51(10), 923-930.

[6] Gorzawski, H. and Hoelderich, W.F. (1999) Transesterification of methyl benzoate and dimethyl terephthalate with ethylene glycol over superbases. Applied Catalysis A: General, 179(1-2), 131-137.

[7] Meyer, U. and Hoelderich, W.F. (1999) Transesterification of methyl benzoate and dimethyl terephthalate with ethylene glycol over basic zeolites. Applied Catalysis A: General, 178(2), 159-166.

[8] El-Toufaili, F.-A., Ahmadniana, F., Dinse, A., Feix, G. and Reichert, K.-H. (2006) Studies on hydrotalcite-catalyzed synthesis of poly(ethylene terephthalate). Macromolecular Materials and Engineering, 291(Pt 4), 11361143.

[9] Serio, M.D., Tesser, R., Ferrara, A. and Santacesaria, E. (2004) Heterogeneous basic catalysts for the transesterification and the polycondensation reactions in PET production from DMT. Journal of Molecular Catalysis A: Chemical, 212(1-2), 251-257.

[10] Falini, Foresti, G.E., Lesci, G. and Roveri, N. (2002) Structural and morphological characterization of synthetic chrysotile single crystals. Chemical Communications, 14, 1512-1513.

[11] Habaue, S., Hirasa, T., Akagi, Y., Yamashita, K. and Kajiwara, M. (2006) Synthesis and property of silicone polymer from chrysotile asbestos by acid-leaching and silylation. Journal of Inorganic and Organometallic Polymers and Materials, 16(2), 155-160.

[12] Habaue, S., Sato, K., Yamashita, K., Shimamura, T., Kaito, M., Masuda, T. and Kajiwara, M. (2008) Polysiloxanes derived from chrysotile asbestos via acid-leaching and silylation processes, Journal of Applied Polymer Science, 110(5), 2891-2897.

[13] Gruner, J.W. (1948) Progress in silicate structures. The American Mineralogist, 33(9-10), 679-691.

[14] Brindley, G.W. and Zussman, J. (1957) A structural study of the thermal transformation of serpentine minerals to forsterite. The American Mineralogist, 42(8), 461-474.

[15] Arai, Y. and Nagai, S. (1963) Chemical Utilization of Serpentine. Chemistry and Chemical Industry, 16(1), 5968. 